\title{
Occurrence of Urinary Crystals among Urinary Tract Infections Suspected Paediatric Patients, Sri Lanka
}

\author{
Amarasinghe KNL, Gunawardana ADUR, Priyadarshani AMB \\ Department of Allied Health Sciences, Faculty of Medical Sciences, \\ University of Sri Jayewardenepura, Sri Lanka.
}

\begin{abstract}
Crystalluria has become one of the most vital biomarkers in urinalysis in detecting several disease conditions. It has been reported that urinary tract infections (UTI) may be the presenting sign of Urolithiasis in children. Therefore, the objective of this study was to identify and estimate the different types of crystals in the urine samples collected from UTI suspected children who admitted to the Lady Ridgeway Hospital for children, Sri Lanka. A descriptive cross-sectional study was conducted using 400 children belong to age $<12$ years suspected with UTI. The participants included 242 males and 158 females. The urine samples were collected prior to start antibiotics. Each sample was examined macroscopically and centrifuged at $2000 \mathrm{rpm}$ for 5 minutes. The urine sediment was examined under the light microscope and different crystal types were identified and counted at x40 magnification. Out of 400 samples 82 samples (82/400) were positive for crystalluria. The crystal types present were uric acid, calcium oxalate, triple phosphate, ammonium biuate and ammonium urate. None of the samples showed abnormal crystal types. The distribution of each crystal type was as follow; uric acid 25/82, calcium oxalate 34/82, triple phosphate 12/82, ammonium biuate 7/82 and ammonium urate 4/82. The quantity of crystals per $m L$ of urine was ranged as follow; uric acid 850-130,000, calcium oxalate 350->250,000, triple phosphate 650-6,000, ammonium biurate and ammonium urate were presented in clumps.
\end{abstract}

KEYWORDS: Crystalluria, Uric Acid, Calcium Oxalate, Triple Phosphate, Ammonium Biurate, Ammonium Urate, Urolithiasis, Urinary Tract Infections

Corresponding author: A.M.B. Priyadarshani, Email: priyadarshani@sjp.ac.lk 


\section{INTRODUCTION}

The excretion of crystals in urine is known as "Crystalluria". It is an outcome derived from pathological conditions or precipitation of certain concentrated chemical constituents in the urine under the normal physiological conditions. Urinary crystals have become one of the most significant biomarkers in urinalysis in detecting several causal metabolic conditions associated with inherited metabolic disorders, bacterial or fungal urinary tract infections (UTI) [Fogazzi, 1996; Baumann and Affolter, 2014]. Furthermore, crystalluria has been implicated in the formation of renal calculi [Daudon et al., 2016; Valentini and Lakshmanan, 2011].

Urolithiasis is a process which undergoes a set of mechanism which eventually converts the stone constituent crystals in the urine in to calculi [Sakandé et al., 2012]. Hence, crystalluria is the initial step of stone formation and it can be used as a biomarker to reveal that the association between the $\mathrm{pH}$ of urine and the possibility to occur stone diseases [Prabhu et al., 2015]. It has been found that crystalluria and urolithiasis can be developed as a result of the UTI [Sakandé et al., 2012; Alpay et al., 2009 ] and the incidence of paediatric lithiasis has drastically increased during the last decade [VanDervoort et al., 2007].

It has been reported that urinary stone disease is a common clinical problem and having of stone in $10 \%$ of the population [Abeygunasekera, 2004]. Furthermore, it has been revealed that the incidence of nephrolithiasis is increasing in females and children [Turney, 2011; Sas, 2010]. Therefore, the objective of present study was to identify and quantify the urinary crystals in the urine samples collected from UTI suspected children who admitted to the Lady Ridgeway
Hospital for Children, Sri Lanka as it is simple and cost-effective method to assess the risk of paediatric lithiasis and the underlying metabolic causes by reflecting the supersaturation of lithiogenic substances.

\section{MATERIALS \& METHODS}

This study was conducted after obtaining ethical approval from the ethical review committee of University of Sri Jayewardenepura, Sri Lanka and Lady Ridgeway Hospital for Children, Sri Lanka.

\subsection{Study population}

Four hundred mid-stream urine samples (volume varied from 10-15 mL) were collected from paediatric male and female subjects (age group - 1day to 12 years) who admitted to the Lady Ridgeway Hospital (OPD and inward) having symptoms of UTI. Clinical examination of the subjects was done by an experienced clinical practitioner. The urine samples were collected prior to start antibiotics, requesting urine culture, antibiotic sensitivity testing (ABST) and urine full report (UFR). The children who sent urine samples to Microbiology laboratory to evaluate the state of recovery of existing UTI were excluded from the study.

\subsection{Study instruments}

Data collection sheets were used to obtain the demographic characteristics of the subjects. The laboratory data collection sheets were used to record the following information of the urine samples; (i) colour (ii) turbidity (iii) volume (iv) $\mathrm{pH}$ (v) crystal (vi) pus cells (vii) epithelial cells (viii) red blood cells (ix) casts. 


\subsection{Sample processing}

\section{Urinalysis}

All the urine samples were collected in to the properly labeled urine containers and were subjected to macroscopic observations. Then the total urine volume was measured and the $\mathrm{pH}$ of each sample was subsequently measured.

\section{Microscopic examination of urine sediment}

Each urine sample was poured in to labeled, cleaned $12 \mathrm{~mL}$ centrifuged tube and centrifuged at 2000 rpm for 5 minutes. The supernatant was decanted and the remaining sediment was resuspended by adding $0.5 \mathrm{~mL}$ of supernatant on to the sediment.

One milliliter of the re-suspended urine sediment was placed on a clean glass slide and covered with a cover slip and then observed under the light microscope. The sediment was scanned using low power objective (x10) and examined under high power objective $(\mathrm{x} 40)$ for different types of crystals, pus cells, epithelial cells, red blood cells, casts and organisms. Each type of these elements were recorded as the average number per high power field (HPF) by scanning 10 high power fields and organism count was recorded in a semi-quantitative manner as $+1,+2,+3,+4$ and field full. Crystal types were differentiated according to their morphological characteristics. Urine deposit from all the samples were obtained within the same day of collection and observed for crystals under the light microscope (x40 objective) within 2 hours of receiving.

\section{Quantitative determination of crystals}

Quantitative determination of crystals was done according to the European Urinalysis Guidelines.

\section{Determination of depth of the fluid layer under} the cover slip

Total urine sediment volume $=0.5 \mathrm{~mL}$

Volume of urine sediment which used for microscopic examination $=0.1 \mathrm{~mL}$

Area under the cover slip $=18 \times 18 \mathrm{~mm}^{2}$

Microscope: ocular 10, objective 40 high power field (HPF) with ocular number 18

HPF diameter $=18 \mathrm{~mm} / 40=0.45 \mathrm{~mm}$

Depth of the fluid layer (h) under cover slip = $0.1 \mathrm{~mL} /(18 \mathrm{x} 18) \mathrm{mm}^{2}$

$=100 \mu \mathrm{L} /(18 \times 18) \mathrm{mm}^{2}$

$=100 \mathrm{~mm}^{3} /(18 \times 18) \mathrm{mm}^{2}=0.3086 \mathrm{~mm}$

\section{Determination of volume of high power field (HPF)}

The volume of high power field (HPF) was calculated according to the European Urinalysis Guidelines (European Urinalysis Guidelines).

Volume of $1 \mathrm{HPF}=\pi \mathrm{r}^{2} \mathrm{~h}$

$=3.14 \times(0.45 / 2)^{2} \mathrm{~mm}^{2} \times 0.3086 \mathrm{~mm}$

$=3.14 \times 0.050625 \mathrm{~mm}^{2} \times 0.3086 \mathrm{~mm}$

$=0.049 \mathrm{~mm}^{3}=0.049 \mu \mathrm{L}$

The number of crystals present was expressed as quantity of crystals/mL of urine. 


\section{RESULTS}

\subsection{Analysis of demographic characters}

The age of the study population was ranged from 1 to 12 years. The majority of the subjects were males (60.5\%), whereas females were $39.5 \%$. Majority of the population $183 / 400$ [45.8\%] belonged to 1-6 years age category while <1 year and 6-12-year category had approximately equal frequency as $98 / 400$ [24.5\%] and 119/400 [29.8\%], respectively.

\subsection{Analysis of biochemical and cellular parameters}

\section{Urine $\mathrm{pH}$ value}

The urinary $\mathrm{pH}$ values of the subjects were ranged from 6.3 to 7.6. Most of the urine samples from subjects with crystalluria (77/82) were acidic. It has been shown that $\mathrm{pH}$ value $>7.0$ was predominantly found in 6-12 year age group while $\mathrm{pH}$ value $<7.0$ were reported mostly in 1-6 years age group.

\section{Pus cells}

The percentage of pyuria in the whole population was $76.3 \% \%$. Out of the patients with crystalluria $(n=82)$ only $20.5 \%$ were presents with pyuria whereas rest of $79.5 \%$ were absent with pyuria.

\section{Red Blood Cells}

The mean red blood cell value of the study population was $1.93 \pm 1.84 / \mathrm{HPF}$. The significant value for haematuria was $>5 / \mathrm{HPF}$. The percentage of haematuria in the whole population was $2 \%$ while no subject having haematuria when crystals were present.

\section{Urine crystals}

In the study population, $20.5 \%$ (82/400) of subjects had crystalluria, whereas $79.5 \%$ (318/400) were absent with urine crystals (see Figure 1).

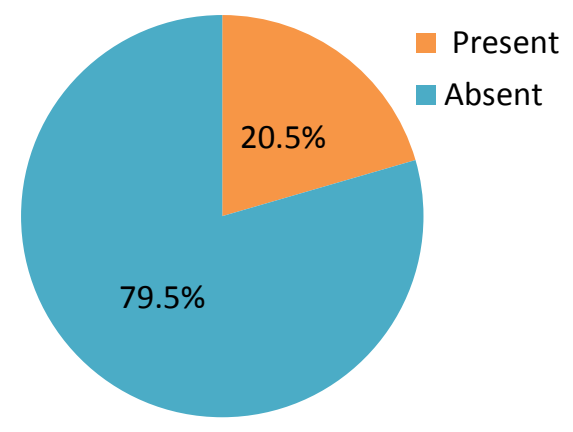

Figure 1: Percentage of subjects with crystalluria

In whole population percentages of females and males with urine crystals were $7 \%$ and $13.5 \%$, respectively (see Figure 2).

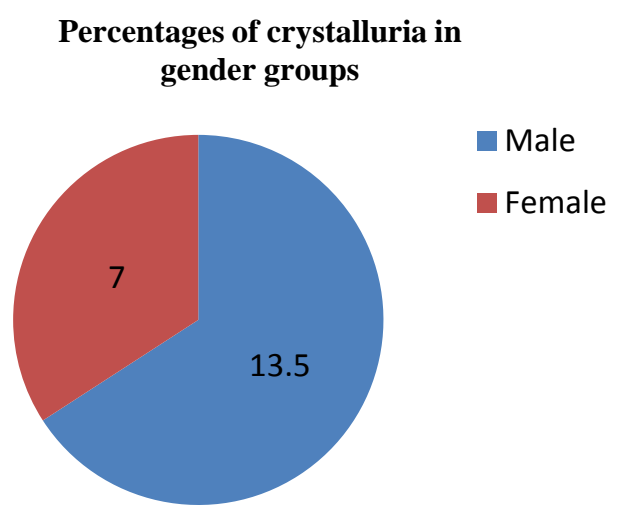


Occurance of crystalluria in males and females

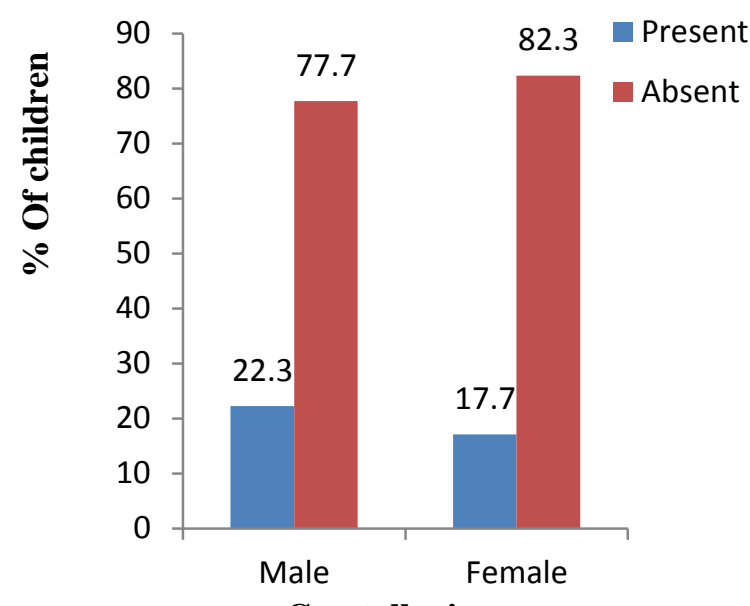

Figure 2: Gender-wise distribution of crystalluria

The distribution of crystalluria had no significant correlation between two gender groups where $p=0.266(p>0.05)$. Among the males, $22.3 \%$ present with crystalluria where as in the females only $17.7 \%$ with crystalluria. The crystal combinations with two types of crystals were identified only in two subjects where calcium oxalate and ammonium burette dominated. One type of crystal was identified among 80 subjects (see Figure 3).

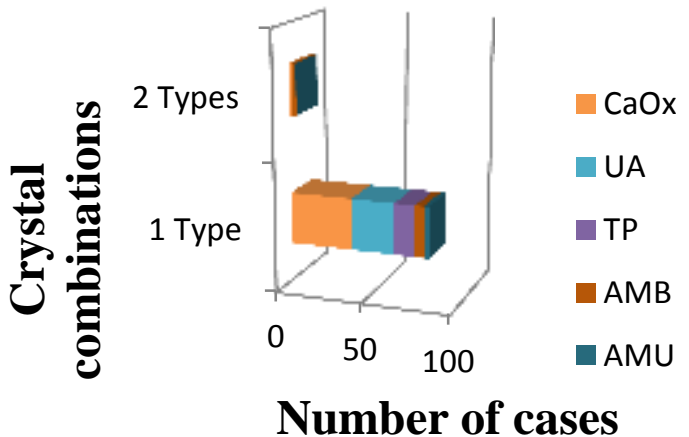

Figure 3: Number of cases with crystal combinations
Where,

CaOX: Calcium oxalate

UA: $\quad$ Uric acid

TP: $\quad$ Triple phosphate

AMB: Ammonium biurate

AMU: Ammonium urate

Percentage of crystal distribution in subjects requested urine full report (UFR) and urine culture reports were $18.5 \%$ and $22.4 \%$, respectively. However, the subjects who requested urine culture reports were more prone to have crystalluria (Table 1).

The percentages of all the crystal types found were higher in the males, compared to the females ie., calcium oxalate (CaOX) 6\%, uric acid (UA) 3.5\%, triple phosphate (TP) 2.3\%, ammonium biurate (AMB)1 \% and ammonium urate (AMU) $0.5 \%$. This is clearly indicated in Figure 4.

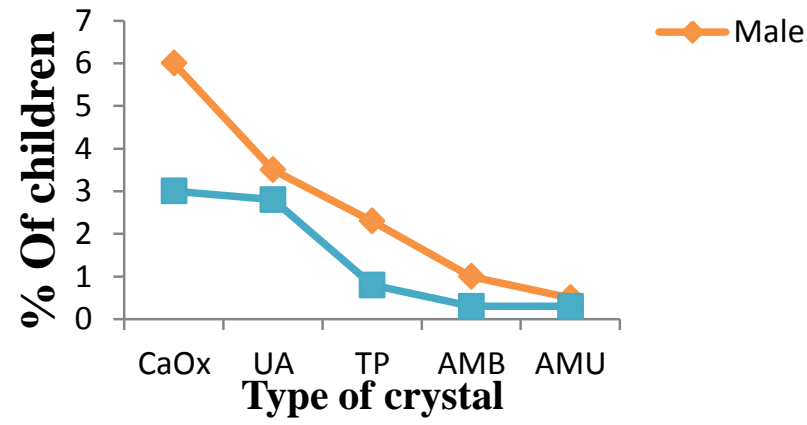

Figure 4: Distribution of crystal types among gender group

Where,

CaOX: Calcium oxalate

UA: Uric acid

TP: $\quad$ Triple phosphate

AMB: Ammonium biurate

AMU: Ammonium urate 
The age-wise distribution of urinary crystals is depicted in Table 2. Among total population $\mathrm{CaOx}, \mathrm{UA}$ and TP were found in $9.0 \%, 6.3 \%$ and $3.0 \%$, respectively followed by least percentages reported in AMB (1.3\%) and AMU $(0.8 \%)$. But no metabolic origin crystals were found among total population. These details are depicted in Figure 5. The quantitative measurement range of crystal count $/ \mathrm{mL}$ of urine is as follow; CaOx (350- $>250,000 / \mathrm{mL})$, UA $(850-130,000 / \mathrm{mL})$ and TP $(650-6,000 / \mathrm{mL})$ and this is given in Table:

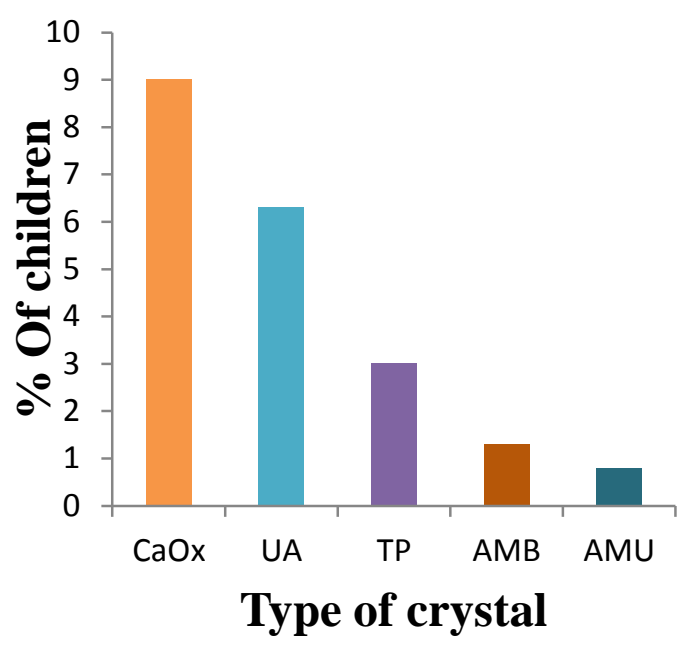

Figure 5: Distribution of different types of crystals among subjects

Where,

CaOX: Calcium oxalate

UA: Uric acid

TP: $\quad$ Triple phosphate

AMB: Ammonium biurate

AMU: Ammonium urate

\section{DISCUSSION}

Crystalluria is a condition which can be easily and frequently found in urine full report. It is a measurement of transient supersaturation of urinary constituents including cyrstallogenic substances via several mechanisms. Formation of crystals can be taken place in-vivo as well as in-vitro depending on the temperature and the $\mathrm{pH}$ of the urine. During urinalysis, identification of crystals is vital in early diagnosis of urolithiasis and underlying pathological conditions such as cystinuria, thereby preventive measures can be taken as early as possible.

A previous study has been shown that calcium oxalate and uric acid stones are more common in stone formers and frequency is higher in men than women. Further, the same study has been highlighted that the knowledge regarding mineralogical composition of urinary stones is important as it is needed to the scientific community to explain the chemistry and the causative factors of the calculi in the urinary system [Keshavarz et al., 2016]. Another study emphasized that the study material consist of 392 chemical analyses of stones from 1,747 patients with urolithiasis revealed that calcium was in $88.3 \%$ of calculi and phosphate as a part of two or three component calculi in $53.7 \%$ of cases. The conformity of incidence of elements in urinary sediment and in uroliths was 64$78 \%$ and consisted $78 \%$ of calcium oxalate, $72 \%$ of phosphate and $64 \%$ of uric acid and urate stone formers [Ochmański et al., 1999]. In the present study children aged 0-12 years suspected UTI were selected as the study population as the children pass metabolic origin urinary crystals are more prone to urolithiasis and the higher incidence of co-existing or recurrent UTI which is a valuable suggestive for 
urolithiasis specially in child population. It has been found that the etiologic factors for urolithiasis could be masked by UTI [Ali and Rifat , 2005, Coward et al., 2003]. Furthermore, it has been reported that the constituents of the stones removed from 273 patients (220 males, 53 females) with bladder stones and 27 patients with urethral stones (males) were as follows; $50.0 \%$ contained magnesium ammonium phosphate (MAP), 39.9\% calcium (oxalate and/or phosphate), 9.4\% uric acid (urate), and $0.7 \%$ cystine. However, urinary infections were found in $59.3 \%$ of patients with MAP stones, $41.2 \%$ with urate stones and $20.0 \%$ with calcium stones. Microbiological analysis has been proved that Proteus species found as the most often bacteria in the infected urine of these patients [Takasaki et al., 1995].

In the present study, five different types of crystals including $\mathrm{CaOX}, \mathrm{UA}, \mathrm{TP}, \mathrm{AMB}$ and AMU have been found out in the study population. The distribution of crystals in study population revealed that considerable prevalence $(78.69 \%)$ in the population aged from 1-12 years. Broadly, the male subjects were more prone to have crystalluria with the prevalence of 20.5\%. Higher tendency for male predisposition to crystalluria has been reported by another study as well [Sakandé et al., 2012]. The result of our study showed that male preponderance which was not compatible with the results of a study done in Barsa city [ Hassan, 2011].

In the present study most of the crystals (93.2\%) were found in the acidic urines. Supportive to this finding another study conducted in India showed that the maximum of crystalluria cases were found where urine is acidic [Prabhu et al., 2015].
In the interpretation of distribution and proportion of crystal types, $\mathrm{CaOX}$ were found as the most abundant type (9.0\%) which was predominantly fond in the children of $<1$-yearold (12.2\%). This was followed by UA (6.3\%) predominant in 1-6 years group (9.3\%) and TP (3.0\%), predominant in 6-12 years group (4.2\%). AMB and AMU were found in $<1 \%$ and this finding is supported by the previous study [Nasert, 2013].

Crystal count per $\mathrm{mL}$ was varied as follows; CaOX (350- >250,000) followed by UA (850$130,000)$ and TP $(650-6,000)$. According to the present study crystalluria is predominantly seen in the age group of 1-6 year and a previous study has been shown that lithiasis is more common in pre-school aged children [Alpay et al., 2009].

In addition to that, urinary crystals were predominantly found in urine samples received for urine culture and antibiotic sensitivity testing compared to urine full report, although in both groups number of subjects was approximately same. Therefore, it is suggested that requirement of examine the urine sediment to screen urinary crystals to prevent the misdiagnosis of lithiasis which can be masked by UTI. Further, present study highlighted that subjects with the symptoms of UTI (81.6\%) were positive for urine crystals but negative for pus cells and microorganisms.

\section{CONCLUSION}

The crystal types present in the study population were uric acid, calcium oxalate, triple phosphate, ammonium biuate and ammonium urate. Uric acid and calcium oxalate were present as the predominant crystal types with 
K.N.L. Amarasinghe, A.D.U.R. Gunawardana \& A.M.B. Priyadarshani

the quantity of $850-130,000$ and $350-$ $>250,000 / \mathrm{mL}$, respectively. None of the samples showed abnormal crystals.

\section{ACKNOWLEDGEMENT}

We would like to express our sincere thanks to the subjects who participated in the study.

\section{REFERENCES}

ABEYGUNASEKERA AM. Urinary stone disease in Sri Lanka. The Ceylon Medical Journal 2004: 49; 41-43 2.

ALI SH, RIFAT UN. Etiological and clinical patterns of childhood urolithiasis in Iraq. Pediatr Nephrol. 2005;20:1453-7.

ALPAY H, OZEN A, GOKCE I, BIYIKLI N. Clinical and metabolic features of urolithiasis and microlithiasis in children. Pediatr Nephrol. 2009;24:2203-9.

BAUMANN JM AND AFFOLTER B. From crystalluria to kidney stones, some physicochemical aspects of calcium nephrolithiasis. WORLD J NEPHROL. 2014; 3(4): 256-267.

COWARD RJ, PETERS CJ, DUFFY PG, CORRY D, KELLETT MJ, CHOONG S, VAN'T H. Epidemiology of pediatric renal stone disease in the UK. Arch Dis Child. 2003;88:962-5.

DAUDON M, FROCHOT $\mathrm{V}$, BAZIN D, JUNGERS P. Crystalluria analysis improves significantly etiologic diagnosis and therapeutic monitoring of nephrolithiasis. Comptes rendus Chim. 2016; 19:1514-1526.

EUROPEAN URINALYSIS GUIDELINES. Scand J Clin Lab Invest Suppl. 2000; 231:1-86.

FOGAZZI GB. Crystalluria: a neglected aspect of urinary sediment analysis. Nephrology Dialysis Transplantation 1996; 11: 379-387

HASSAN JK. Crystalluria types and incidence in Basra City; southern of Iraq. Journal of Basrah Researches (Sciences) 2011;37:72-81.

KESHAVARZIB, ASHAYERINY, MOORE F, IRANID, ASADIS, ZARASVANDIA, SALAR M. Mineralogical composition of urinary stones and their frequency in patients: Relationship to gender and age. Minerals. 2016;131; doi:10.3390/min6040131.

NASERT M. Urolithiasis in Asian children: Evaluation of metabolic factors. J Paediatr Biochem. 2013;3:225-38.

Analysis OCHMAŃSKI W, KMIECIK J, SUŁOWICZ W. of Chemical Composition of Urinary Stones, IntUrol Nephrol.1999;31: 743750 .

PRABHU N, MUBARAK S, MARZUK M, BANTHAVI SP, SUNDHARARAJAN A, UMA A, SARADA V. Prevalence of crystalluria and its association with Escherichia coli urinary tract infections. Int J Res Med Sci. 2015;3:1085-90.

SAKANDÉ J, DJIGUEMDE R, NIKIÉMA A, KABRÉ E, SAWADOGO M. Survey of urinary crystals identified in residents of Ouagadougou , 
BURKINA FASO: Implications for the diagnosis and management of renal dysfunctions. Biokemistri 2012;24:123-8.

SAS D. Increasing incidence of kidney stones in children evaluated in the emergency department. Journal of Paediatrics 2010: 157; 132-137

TAKASAKI E, SUZUKI T, HONDA M, IMAI T, MAEDA S \& HOSOYA Y. Chemical compositions of 300 lower urinary tract calculi and associated disorders in the urinary tract, Urol Int. 1995;54:89-94.

TURNEY BW. Trends in urological stone disease British Journal of Urology International 2011; 24: 382-386 3.

VALENTINI RP, LAKSHMANAN Y. Nephrolithiasis in Children. Adv Chronic Kidney Dis. 2011;18:370-5.

VAN DERVOORT K, WIESEN J, FRANK R, VENTO S, CROSBY V, CHANDRA M, ET AL. Urolithiasis in Pediatric Patients: A single center study of incidence, clinical presentation and outcome. J Urol. 2007;177:2300-5.

AGRAWAL A. JAFFE JF. \& MANDELKER GN. The post-merger performance of acquiring firms: a re-examination of an anomaly, Journal of Finance. 1992; Vol. 47, pp. 1605-21.

ANDRE P. KOOLI M. \& L'HER J. The longrun performance of mergers and acquisitions: evidence from the Canadian Stock Market", Financial Management. 2004; Vol. 33, pp. 2743.

BEENA PL. An Analysis of Mergers in the Private Corporate Sector in India", Centre for
Development Studies, Thiruvananthapuram. 2000; Working Paper No 301.

CANAGAVALLY R. An Evaluation of Mergers and Acquisitions", M.Phil Dissertation (Unpublished), Pondicherry University, Pondicherry. 2000.

PATRO DK. TUCKMAN H. \& WANG X. Do mergers and acquisitions create shareholder wealth in the pharmaceutical industry? International Journal of Pharmaceutical and Healthcare Marketing. 2007. Vol. 1 No. 1, 2007, pp. 58-78.

SINHA N. KAUSHIK KP. CHAUDHARY T. Measuring Post Merger and Acquisition Performance: An Investigation of Select Financial Sector Organizations in India, International Journal of Economics and Finance. 2010; Vol. 2, No. 4; November 2010, 190-200.

GHOSH A. Does operating performance really improve following corporate acquisitions? Journal of Corporate Finance. 2001; 7 pp 151178

HEALY PM. PALEPU KG. \& RUBACK RS. Does corporate performance improve after mergers?, Journal of Financial Economics. 1992; Vol. 33 No. 2, pp. 135-76.

LODERER C. \& MARTIN K. Post-Acquisition Performance of Acquiring Firms, Financial Management. 1992; Vol 21, No 3, pp 69-79.

LUBATKIN M. Mergers and Performance of the Acquiring Firm, Academy of Management Review. 1983; Vol. 8, No. 2, April, pp 218-225 
K.N.L. Amarasinghe, A.D.U.R. Gunawardana \& A.M.B. Priyadarshani

MARTYNOVA M. OOSTING S. \& SIDHARTH S \& SUNIL G. Comparison of RENNEBOOG L. The long-term operating Post-Merger performance of Acquiring Firms performance of European Acquisitions, International Mergers and Acquisitions Activity since 1990: Quantitative Analysis and Recent Research, G.Gregoriou and L. Renneboog (eds.), Massachusetts: Elsevier. 2007; pp 1-40.

SELVAM M. BABU M. INDHUMATHI G. EBENEZER B. Impact of mergers on the corporate performance of acquirer and target companies in India" Journal of Modern Accounting and Auditing. 2009; Vol.5, No.11 (Serial No.54)

GAUGHAN PA. Mergers, Acquisitions, and Corporate Restructurings, 2nd ed. New York: John Wiley \& Sons. 1999; 21-60.

MANTRAVADI P. \& REDDY A.V. PostMerger Performance of Acquiring Firms from Different Industries in India" International Research Journal of Finance and Economics. 2008; Issue 22: EuroJournals Publishing, Inc. 2008.

MAHAMUNI PN \& JUMLE AG. Measuring Post Merger Operating Performance of Acquiring Firms of Food \& Beverages Industries in India, Published in Pezzottaite Journals, International Journal of Retailing \& Rural Business Perspectives, A Refereed Quarterly Journal. 2012; 2279-0934 \& 22790942

VANITHA S. \& SELVAM M. Financial Performance of Indian Manufacturing Companies During Pre and Post Merger International Research Journal of Finance and Economics. 2007; Issue 12 EuroJournals Publishing, Inc. (India) involved in Domestic and Cross-border acquisitions MPRA. Paper. 2009; No. 19274.

KAUR S. A Study of Corporate Takeovers in India, Ph.D Dissertation (Unpublished), University of Delhi, New Delhi. 2002. 